\title{
Security in Databases using Cloud Computing
}

\author{
K. Yugendhar, Sangeetha.S, Vimala D
}

\begin{abstract}
The initiation of the Internet of Things is the fundamental stimulus behind the current mechanical surprise. Web of things is the unavoidable aggregation of web related devices that assemble, look at and change the immense measure of colossal data at an incomparable rate. By creating and passing on sensible preprocessing frameworks, this goliath measurement of data can be transformed into performance information. The all-new IoT tremendous information development expects changes to be passed on to the present advances. The significance of preprocessing methodologies in the IoT enormous information situation has been discussed in this document and in addition to early IoT examines huge information preprocessing frameworks. Finally, a bright fresh parallel preprocessing system for IoT Big data has been suggested to transform the tough data into treasurable information so that enormous data examination of IoT performance can obtain complete recognition of this increasing growth.
\end{abstract}

Keywords-Big Data; IoT; examination; Hadoop delineate

\section{INTRODUCTION}

The internet of stuff declared as the mechanical disturbances that follows is not another idea. This concept had just been regarded by Kevin Ashton, one of the founders in the mid-2000s[1-3]. The Internet of Things (IoT) is a vital component of the potential internet. It alludes to the gathering of shrewdly associated gadgets and frameworks having one of a kind personalities, empowering consistent correspondence between the essential world entities [4-9]. The enormous information is depicted by four qualities to be specific volume, speed, assortment and veracity. It is the enormous amount of information that streams in a variety of sizes at an unparalleled pace. Since it is extremely big,it can't be handled utilizing customary procedures or devices [10-16].IoT and enormous information joining will release a lot of chances that will enhance the personal satisfaction of consumers. The web of things creates immense measure of heterogeneous information, for example, machine information, sensor information, climate information, geospatial information, satellite information, RFID information, content, picture, sound, video information and so forth [17-20]. The tremendous measure of huge

Revised Manuscript Received on July 22, 2019.

K. Yugendhar, Student Department of Information Technology, Bharath Institute of Higher Education and Research, Chennai, India Email: yugendhark887@gmail.com

Sangeetha.S Department of CSE,Bharath Institute of Higher Education \& Research,TamilNAdu, India Email: sangeethasathya01@gmail.com

Vimala D Department of CSE,Bharath Institute of Higher Education \& Research,TamilNAdu, India Email: vimalamuthu3@gmail.com information delivered by the IoT gadgets contains shrouded fortune of data blended with bothersome information.

The IoT enormous data may alter in settings and buildings due to the dissimilar sources, expelling copy information, building a bound together blueprint by coordinating information from various sources [21-26]. The IoT enormous data may alter in settings and buildings due to the dissimilar sources. Pre-processing data will not involve confusion in the management of missing data, The real impediments preventing the advantages are to be overpowered by conveying the reasonable preprocessing strategies to understand the maximum capacity of IoT enormous information. IoT huge information preprocessing procedures should work undauntedly to enhance information quality and to empower quick and precise information mining to disentangle the concealed learning behind the crude data [27-29]. The IoT huge information preprocessing structure assembled utilizing the huge information instruments like open source Hadoop, is expected to wipe out important information from the profitable ones [30-32].

The aim of this document is to include the obviousness of pre-dealing with frameworks in the IoT enormous information situation; to address early explorations of massive information pre-processing techniques in IoT ; to suggest a new IoT tremendous data parallel pre-processing framework to be established using the Hadoop blueprint framework to pre-process the enormous amount of enormous information provided by the IoT

\section{IOT BIG DATA PREPROCESSING}

IoT huge information preprocessing incorporates information cleaning, information reconciliation, information change and information lessening. The enormous information produced by IoT gadgets will be in different configurations and structures. This information might be to a great degree influenced by bothersome components, for example, exceptions, commotion, missing esteems, questionable

repetitive information. So preprocessing ends up noticeably obligatory to credit missing esteems, to kill copies, to perform information coordination with the aim of building an incorporated composition, Before putting it in the database, change the cleaned and structured information to the ordinary configuration. If the preprocessing stage has not been correctly conducted, deluding will occur promptly. It suggests that IoT enormous information quality is straightforwardly relative to the IoT huge information preprocessing [33-38]. Everywhere, the IoT enormous information preprocessing require considerable measure of preparing time. The current strategies and calculations are not 


\section{Security in Databases using Cloud Computing}

appropriate to deal with high dimensional IoT huge information. Revealing useful data from the IoT ocean and implementing suitable pre-processing efforts that best suit the data sets selected is an endless specific exam.

In context of that, Innovative figurings and frameworks are required to deal with this issue. The resulting dataset will be sent IoT giant information examination at the stage where all preprocessing tasks have been completed. Structure for developing sensor information purifying frameworks in view of spatial and fleeting highlights to clean sensor information. The framework was also sent to a canny house to demonstrate its capacity to clean information. Saul Gill et al. created a information cleaning system to clear up huge amounts of spouting information. First, the cleaning limits were performed using Streams-Esper, and some time later, using $\mathrm{R}$, the filtered data was transformed into desire models. Finally, special cases were recognized and removed by the produced designs in the DCS. [38],[40]

Mervat Abu-Elkheir et al. [1] have overviewed information administration answers for web of things. Outline primitives including information gathering, information administration and handling of information administration arrangements have been talked about. The life expectancy of information inside an IoT framework beginning from information age, gathering likewise clarified. Finally, the IoT information organisation structure was suggested. Katarina Grolinger et al. used Map Reduce to help better structure huge data projects to summarize the issues and challenges in managing tremendous data. Mugdha Jain et al. have projected an novel derived estimation in perspective on $\mathrm{k}$-expects to vanquish the burden of customary k-suggests computation which had obscure number of cycles. The proposed calculation has decided the quantity of emphasess without trading off the exactness in this manner empowering rapid and precise huge information investigation [39-41].

proposed calculation can deal with absolute information simply after its proportionate change to mathematical information.

Michael Shindler et al. suggested quick and accurate counting of k-suggests for significant datasets. Regardless, memory measure is sweeping through this computation. AlfioFerrarai et al. have given a entire audit on different procedures for information associating with produce a social event of mappings to interface dissent delineations in heterogeneous information basis. Additionally the information connecting strategies have been sorted in view of granularity, sort and wellspring of the confirmation. Charu C. Aggarwal et al. researched stuff on the internet from a viewpoint guided by data. Additionally, data cleaning and mining problems recognized with IoT's enormous data marvel were examined.

By suggesting current institutionalization schemes, S.Gopal Krishna Patro et al. suggested a whole number scaling approach for institutionalization, Using the HDFS framework, Ruay-Shiung Chang et al. suggested a vibrant deduplication approach to improve the restriction use of a server ranch. Duplicates were abstained from manufacturing better performance could be grown precisely when the

accumulating room using deduplication strategy. But the quality of information resolute could not be guaranteed when the extra space has reached certain limit.

\section{RESULTS}

Available pre-processing policies limit significant data or all around characterized mistake models [4]. By the by, for the developing IoT huge information area, there exist no pre-characterized requirements or all around characterized mistake models. IoT huge information is regularly voluminous, boisterous, awkward, heterogeneous, unstructured and problematic. Actually preprocessing strategies expected to deal with IoT huge information are on a very basic level not quite the same as the current preprocessing procedures The efficiency of cutting-edge data mining calculations is directly consistent with the capacity of overhauled preprocessing techniques.

By transferring the proposed IoT gigantic data parallel preprocessing framework depending on the Hadoop representation structure, preprocessing assignments such as data cleaning, data attachment, data change and data deletion will be performed to reduce the range of the data set to upgrade speed management, as far as possible the enthusiasm for data extra space and to change the rough IoT enormous data in to quality data to support quality assessment. [1],[3],[5]

\section{REFERENCES}

[1] Y Kumarave A., Rangarajan K.,Algorithm for automaton specification for exploring dynamic labyrinths,Indian Journal of Science and Technology,V-6,I-SUPPL5,PP-4554-4559,Y-2013

[2] P. Kavitha, S. Prabakaran "A Novel Hybrid Segmentation Method with Particle Swarm Optimization and Fuzzy C-Mean Based On Partitioning the Image for Detecting Lung Cancer" International Journal of Engineering and Advanced Technology (IJEAT) ISSN: 2249-8958, Volume-8 Issue-5, June 2019

[3] Kumaravel A., Meetei O.N.,An application of non-uniform cellular automata for efficient cryptography,2013 IEEE Conference on Information and Communication Technologies, ICT 2013,V-,I-,PP-1200-1205,Y-2013

[4] Kumarave A., Rangarajan K.,Routing alogrithm over semi-regular tessellations, 2013 IEEE Conference on Information and Communication Technologies, ICT 2013,V-,I-,PP-1180-1184,Y-2013

[5] P. Kavitha, S. Prabakaran "Designing a Feature Vector for Statistical Texture Analysis of Brain Tumor" International Journal of Engineering and Advanced Technology (IJEAT) ISSN: 2249-8958, Volume-8 Issue-5, June 2019

[6] Dutta P., Kumaravel A.,A novel approach to trust based identification of leaders in social networks,Indian Journal of Science and Technology,V-9,I-10,PP--,Y-2016

[7] Kumaravel A., Dutta P.,Application of Pca for context selection for collaborative filtering,Middle - East Journal of Scientific Research,V-20,I-1,PP-88-93,Y-2014

[8] Kumaravel A., Rangarajan K.,Constructing an automaton for exploring dynamic labyrinths,2012 International Conference on Radar, Communication and Computing, ICRCC 2012,V-,I-,PP-161-165,Y-2012

[9] P. Kavitha, S. Prabakaran "Adaptive Bilateral Filter for Multi-Resolution in Brain Tumor Recognition" International Journal of Innovative Technology and Exploring Engineering (IJITEE) ISSN 
2278-3075, Volume-8 Issue-8 June, 2019

[10] Kumaravel A.,Comparison of two multi-classification approaches for detecting network attacks,World Applied Sciences Journal,V-27,I-11,PP-1461-1465,Y-2013

[11] Tariq J., Kumaravel A.,Construction of cellular automata over hexagonal and triangular tessellations for path planning of multi-robots,2016 IEEE International Conference on Computational Intelligence and Computing Research, ICCIC 2016,V-,I-,PP--,Y-2017

[12] Sudha M., Kumaravel A.,Analysis and measurement of wave guides using poisson method,Indonesian Journal of Electrical Engineering and Computer Science,V-8,I-2,PP-546-548,Y-2017

[13] Ayyappan G., Nalini C., Kumaravel A.,Various approaches of knowledge transfer in academic social network,International Journal of Engineering and Technology,V-,I-,PP-2791-2794,Y-2017

[14] Kaliyamurthie, K.P., Sivaraman, K., Ramesh, S. Imposing patient data privacy in wireless medical sensor networks through homomorphic cryptosystems 2016, Journal of Chemical and Pharmaceutical Sciences 92.

[15] Kaliyamurthie, K.P., Balasubramanian, P.C. An approach to multi secure to historical malformed documents using integer ripple transfiguration 2016 Journal of Chemical and Pharmaceutical Sciences 92.

[16] A.Sangeetha,C.Nalini,"Semantic Ranking based on keywords extractions in the web", International Journal of Engineering \& Technology, 7 (2.6) (2018) 290-292

[17] S.V.GayathiriDevi,C.Nalini,N.Kumar,"An efficient software verification using multi-layered software verification tool "International Journal of Engineering \& Technology, 7(2.21)2018 454-457

[18] C.Nalini,ShwtambariKharabe,"A Comparative Study On Different Techniques Used For Finger - Vein Authentication", International Journal Of Pure And Applied Mathematics, Volume 116 No. 8 2017, 327-333, Issn: 1314-3395

[19] M.S. Vivekanandan and Dr. C. Rajabhushanam, "Enabling Privacy Protection and Content Assurance in Geo-Social Networks", International Journal of Innovative Research in Management, Engineering and Technology, Vol 3, Issue 4, pp. 49-55, April 2018.

[20] Dr. C. Rajabhushanam, V. Karthik, and G. Vivek, "Elasticity in Cloud Computing", International Journal of Innovative Research in Management, Engineering and Technology, Vol 3, Issue 4, pp. 104-111, April 2018.

[21] K. Rangaswamy and Dr. C. Rajabhushanamc, "CCN-Based Congestion Control Mechanism In Dynamic Networks", International Journal of Innovative Research in Management, Engineering and Technology, Vol 3, Issue 4, pp. 117-119, April 2018.

[22] Kavitha, R., Nedunchelian, R., "Domain-specific Search engine optimization using healthcare ontology and a neural network backpropagation approach", 2017, Research Journal of Biotechnology, Special Issue 2:157-166

[23] Kavitha, G., Kavitha, R., "An analysis to improve throughput of high-power hubs in mobile ad hoc network", 2016, Journal of Chemical and Pharmaceutical Sciences, Vol-9, Issue-2: 361-363

[24] Kavitha, G., Kavitha, R., "Dipping interference to supplement throughput in MANET", 2016, Journal of Chemical and Pharmaceutical Sciences, Vol-9, Issue-2: 357-360

[25] Michael, G., Chandrasekar, A.,"Leader election based malicious detection and response system in MANET using mechanism design approach", Journal of Chemical and Pharmaceutical Sciences(JCPS) Volume 9 Issue 2, April - June 2016.

[26] Michael, G., Chandrasekar, A.,"Modeling of detection of camouflaging worm using epidemic dynamic model and power spectral density", Journal of Chemical and Pharmaceutical Sciences(JCPS) Volume 9 Issue 2, April - June 2016

[27] Pothumani, S., Sriram, M., Sridhar, J., Arul Selvan, G., Secure mobile agents communication on intranet,Journal of Chemical and Pharmaceutical Sciences, volume 9, Issue 3, Pg No S32-S35, 2016

[28] Pothumani, S., Sriram, M., Sridhar, Various schemes for database encryption-a survey, Journal of Chemical and Pharmaceutical Sciences, volume 9, Issue 3, Pg NoS103-S106, 2016

[29] Pothumani, S., Sriram, M., Sridhar, A novel economic framework for cloud and grid computing, Journal of Chemical and Pharmaceutical Sciences, volume 9, Issue 3, Pg No S29-S31, 2016

[30] Priya, N., Sridhar, J., Sriram, M. "Ecommerce Transaction Security Challenges and Prevention Methods- New Approach” 2016 ,Journal of Chemical and Pharmaceutical Sciences, JCPS Volume 9 Issue 3.page no:S66-S68

[31] Priya, N.,Sridhar,J.,Sriram, M."Vehicular cloud computing security issues and solutions" Journal of Chemical and Pharmaceutical Sciences(JCPS) Volume 9 Issue 2, April - June 2016

[32] Priya, N., Sridhar, J., Sriram, M. "Mobile large data storage security in cloud computing environment-a new approach" JCPS Volume 9 Issue 2. April - June 2016
[33] Anuradha.C, Khanna.V, "Improving network performance and security in WSN using decentralized hypothesis testing "Journal of Chemical and Pharmaceutical Sciences(JCPS) Volume 9 Issue 2, April - June 2016.

[34] Anuradha.C, Khanna.V, "A novel gsm based control for e-devices" Journal of Chemical and Pharmaceutical Sciences(JCPS) Volume 9 Issue 2, April - June 2016

[35] Anuradha.C, Khanna.V, "Secured privacy preserving sharing and data integration in mobile web environments " Journal of Chemical and Pharmaceutical Sciences(JCPS) Volume 9 Issue 2, April - June 2016.

[36] Sundarraj, B., Kaliyamurthie, K.P. Social network analysis for decisive the ultimate classification from the ensemble to boost accuracy rates 2016 International Journal of Pharmacy and Technology 8

[37] Sundarraj, B., Kaliyamurthie, K.P. A content-based spam filtering approach victimisation artificial neural networks 2016 International Journal of Pharmacy and Technology 83.

[38] Sundarraj, B., Kaliyamurthie, K.P. Remote sensing imaging for satellite image segmentation2016 International Journal of Pharmacy and Technology 83.

[39] Sivaraman, K., Senthil, M. Intuitive driver proxy control using artificial intelligence 2016 International Journal of Pharmacy and Technology 84

[40] Sivaraman, K., Kaliyamurthie, K.P. Cloud computing in mobile technology 2016 Journal of Chemical and Pharmaceutical Sciences 92.

[41] Sivaraman, K., Khanna, V. Implementation of an extension for browser to detect vulnerable elements on web pages and avoid click jacking 2016 Journal of Chemical and Pharmaceutical Sciences 92

\section{AUTHORS PROFILE}

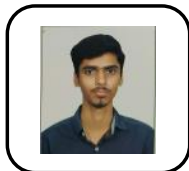

K. Yugendhar, Student Department of Information Technology, Bharath Institute of Higher Education and Research, Chennai, India

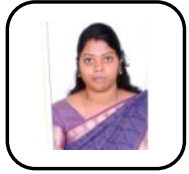

Sangeetha.S Assistant ProfessorDepartment of CSE,Bharath Institute of Higher Education \& Research,TamilNAdu, India

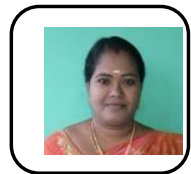

Vimala.D Assistant Professor Department of CSE,Bharath Institute of Higher Education \& Research,TamilNAdu, India 